\title{
Lung hyperpermeability and asthma prevalence in schoolchildren: unexpected associations with the attendance at indoor chlorinated swimming pools
}

\author{
A Bernard, S Carbonnelle, O Michel, S Higuet, C de Burbure, J-P Buchet, C Hermans, \\ X Dumont, I Doyle
}

Occup Environ Med 2003;60:385-394 See end of article for
authors' affiliations

Correspondence to: Dr A Bernard, Unit of Toxicology, Catholic

University of Louvain, 30.54 Clos

Chapelle-aux-Champs, B-1200 Brussels, Belgium; bernard@toxi.ucl.ac.be

Accepted 12 September 2002

\begin{abstract}
Aims: To study whether exposure to nitrogen trichloride in indoor chlorinated pools may affect the respiratory epithelium of children and increase the risk of some lung diseases such as asthma.

Methods: In 226 healthy children, serum surfactant associated proteins A and B (SP-A and SP-B), 16 $\mathrm{kDa}$ Clara cell protein (CC16), and lgE were measured. Lung specific proteins were measured in the serum of 16 children and 13 adults before and after exposure to $\mathrm{NCl}_{3}$ in an indoor chlorinated pool. Relations between pool attendance and asthma prevalence were studied in 1881 children. Asthma was screened with the exercise induced bronchoconstriction test (EIB).

Results: Pool attendance was the most consistent predictor of lung epithelium permeability. A positive dose-effect relation was found with cumulated pool attendance and serum SP-A and SP-B. Serum lgE was unrelated to pool attendance, but correlated positively with lung hyperpermeability as assessed by serum SP-B. Changes in serum levels of lung proteins were reproduced in children and adults attending an indoor pool. Serum SP-A and SP-B were already significantly increased after one hour on the pool side without swimming. Positive EIB and total asthma prevalence were significantly correlated with cumulated pool attendance indices.

Conclusions: Regular attendance at chlorinated pools by young children is associated with an exposure dependent increase in lung epithelium permeability and increase in the risk of developing asthma, especially in association with other risk factors. We therefore postulate that the increasing exposure of children to chlorination products in indoor pools might be an important cause of the rising incidence of childhood asthma and allergic diseases in industrialised countries. Further epidemiological studies should be undertaken to test this hypothesis.
\end{abstract}

$\mathrm{F}$ or several decades, chlorination has been used to destroy microbiological pathogens and organic matter in swimming pools. The most commonly used product is sodium or calcium hypochlorite, but other chlorine compounds such as dichloroisocyanurate or chlorine gas are sometimes used. In water, all these compounds release hypochlorous acid, a powerful oxidant which is the active biocide. When reacting with organic matter brought by swimmers (for example, urine, sweat), hypochlorous acid generates a complex mixture of potentially harmful disinfection byproducts including trihalomethanes, trihaloacetic acids, and chloramines. ${ }^{1}$ These compounds are actively inhaled by swimmers, either as gases or in the form of aerosols, depending on their volatility and water solubility. Of these byproducts, the most volatile and also most concentrated in the air of indoor pools is nitrogen trichloride $\left(\mathrm{NCl}_{3}\right) .^{2{ }^{3}} \mathrm{NCl}_{3}$ is a powerful irritant, probably responsible for the eye and upper respiratory tract irritation felt by lifeguards and other pool attenders. ${ }^{4}$ In rodents, this gas has the same irritating potency as chlorine or formaldehyde, and causes fatal lung oedema at high doses. ${ }^{6} \mathrm{NCl}_{3}$ is also responsible for the acute lung injury in accidental exposures to chlorine based disinfectants and cleaning agents. ${ }^{7-9}$

While the acute respiratory toxicity of chlorination products has been known for a long time, information concerning the potential risks of chronic exposure to these irritants in indoor pools is very scarce, being limited to one study on lifeguards. ${ }^{4}$ This study did not find a relation between $\mathrm{NCl}_{3}$ exposure, indices of lung function, and bronchial hyperreactivity, but because of a selection bias, the authors did not exclude the possibility of chronic effects. Furthermore, these observations cannot be extrapolated to swimmers actively inhaling air at the surface of the water.

Although swimming pools are attended by millions of people worldwide, apparently no epidemiological study has so far been carried out to ascertain whether in certain conditions chlorine disinfectants and their byproducts can represent a health hazard for recreational swimmers and especially for young children who are the most frequent attendees of these establishments. The belief that the swimming pool environment is safe is so deeply rooted in our minds that it is regarded as a healthy practice to send schoolchildren swimming as frequently as possible-much more than necessary for swimming training-even from the youngest age. This lack of concern is also reflected in the existing regulations, which in most countries, including the USA, are focused on the microbiological quality of pool water, largely ignoring the air quality.

Recently, our group has developed a new, non-invasive approach, allowing the detection of subclinical changes of the respiratory epithelium caused by air pollutants and other insults. This approach, referred to as pneumoproteinaemia, is based on the determination in serum of lung specific proteins, reflecting the permeability or the cellular integrity of the lung epithelial barrier. ${ }^{10}$ So far, three proteins have been validated

Abbreviations: ANOVA, analysis of variance; BMI, body mass index; CC16, 16 kD Clara cell protein; EIB, exercise induced bronchoconstriction test; ETS, environmental tobacco smoke; PEF, peak expiratory flow; SP-A, surfactant associated protein A; SP-B, surfactant associated protein $B$ 
as non-invasive tests of lung epithelial damage: the antioxidant $16 \mathrm{kDa}$ Clara cell protein $(\mathrm{CCl})$ and the alveolar surfactant associated proteins A and B (SP-A and SP-B). These proteins have been validated as blood markers of lung epithelium hyperpermeability in a variety of acute or chronic lung disorders. ${ }^{11}$ Because of their sensitivity and noninvasiveness, these tests can also be used to determine effects of air pollutants on the pulmonary epithelium that are undetected by usual tests. ${ }^{12}$ Serum CC16 can also serve as a marker of chronic Clara cell injury caused by tobacco smoke ${ }^{13}{ }^{14}$ or other lung irritants. ${ }^{15}$

By applying these new tests in an epidemiological study planned to assess the chronic effects of urban air pollutants on the respiratory tract of children, we unexpectedly found that the main factor affecting the lung epithelium of children was the regular attendance of an indoor chlorinated pool. Pursuing our investigations, we found that these effects were most likely caused by repeated exposure to $\mathrm{NCl}_{3}$ and that regular chlorinated pool attendance was strongly associated with an increased risk of developing asthma.

\section{MATERIALS AND METHODS}

\section{Study of chronic effects on the lung epithelium}

The protocol of the study was approved by the ethical committee of the Faculty of Medicine, Catholic University of Louvain. Children were recruited from seven primary schools with a kindergarten, two located in an urban area (Brussels) and five in a rural area (Ardenne). Both for blood sampling and to avoid possible functional changes associated with puberty, only children of the fourth and fifth grades of primary school were invited to participate. They were examined after their parents had given written informed consent and completed a self administered questionnaire inquiring about recurrent respiratory symptoms (during the past 12 months) and environmental and lifestyle factors likely to affect the lung epithelium.

Of a total of 440 families contacted, 255 (58\%) agreed for their child to take part in the study and provide a blood sample. The response rates in the two Brussels schools $(41 \%$ and $43 \%)$ were lower than in the five schools in the rural area $(67 \%, 78 \%, 83 \%, 89 \%$, and $100 \%)$, most likely as a result of the socioeconomic and cultural differences between the populations living in Brussels downtown or in rural areas in the south of Belgium. However, no statistically significant difference was found between responders and non-responders in the lifestyle or environmental factors likely to affect the respiratory tract (body mass index (BMI); exposure to pets, to mould, or to gas stove emissions; housing density; sporting activity, including swimming; house with double-glazed windows). The only difference found between responders and non-responders concerned the exposure to environmental tobacco smoke (ETS), which was more frequent in responders $(50.4 v 29.4 \%, \mathrm{p}=0.044)$.

Blood samples were obtained from 235 children, of whom nine were identified by the questionnaire as being treated for asthma. Since these children might present lung epithelium changes secondary to inflammatory reactions associated with asthma, we decided to exclude them in order to better assess the effects of air pollution, even though inclusion of these nine subjects did not alter the results. The final population thus consisted of 226 children, 79 recruited from two primary schools in Brussels and 147 from five primary schools in the Ardenne.

Information on school pool attendance was provided by school directors. In the seven schools, pool attendance was compulsory, children being exempted only on the basis of a medical certificate. In Brussels, all children attended a swimming pool fortnightly, from the age of 6 in one school and from the age of 8 in the other. In the rural area, pool attendance was more variable as children from one school were unable to attend a school pool, while others attended the school pool weekly from the age of 2.5 or 6 years onwards. The five swimming pools used sodium hypochlorite to sanitise the water. The concentrations of active chlorine in water (hypochlorite/ hypochlorous acid) were within recommended limits in Belgium (0.5-1.5 mg/l). Children were examined in March and April to avoid acute effects of ambient ozone on the lung epithelium. ${ }^{12}$ As they were examined during school time, children absent for respiratory infections were excluded. Height and body weight were recorded; after application of an anaesthetic cream (Emla, Astra-Zeneca, Sweden), $7.5 \mathrm{ml}$ of venous blood were withdrawn.

\section{Study of acute effects on the lung epithelium}

The protocol of the study was also approved by the ethical committee of the Faculty of Medicine, Catholic University of Louvain. The experiment was carried out in a public chlorinated indoor pool on 16 children aged 5-14 years (mean 9.6 years) and 13 adults aged $26-47$ years (mean 36.9 years). All volunteers were healthy subjects recruited among the University of Louvain staff and their families or relatives. Subjects participated in the study after having given a written informed consent. For children, written approval was obtained from their parents, most of whom also volunteered for the study. The concentration of $\mathrm{NCl}_{3}$ was measured at $1.5 \mathrm{~m}$ as described by Hery and colleagues. ${ }^{3}$ Children were allowed to have free activities - playing for the youngest and swimming for the oldest. Adults were asked to stay on the pool side for one hour without swimming, then to swim freely during the second hour (swimming time was 15-45 minutes, depending on the subject). Blood samples $(7.5 \mathrm{ml})$ were taken from all subjects, the first before entering the pool (one missing sample in adults), then after two hours attendance for children and after one and two hour attendance for adults (one missing sample in adults at 2 hours).

\section{Study of the relations between childhood asthma and pool attendance}

The associations between asthma prevalences and indoor pool attendance were studied by retrospectively analysing the data from an asthma survey conducted in Brussels between 1996 and 1999. This survey, carried out prior to the two preceding studies, was primarily intended to evaluate the asthma prevalence in a large population of schoolchildren in Brussels. The protocol of this study was approved by the ethical committee of the St Pierre University Hospital. Children were examined after their parents had given written informed consent. A total of 1881 children aged 7-14 years were recruited from 15 primary schools in Brussels, all including a kindergarten section. The participation rate was higher than $98 \%$ in all schools. Examinations took place between 1996 and 1999.

Data on health status, respiratory symptoms, ${ }^{16}$ and environmental or lifestyle variables (socioeconomic status based on parental education, exposure to pets, to ETS, etc) were obtained by a self administered questionnaire filled in by the parents. Asthma was screened using the exercise induced bronchoconstriction test (EIB), ${ }^{17}$ consisting of measurement of the fall of peak expiratory flow (PEF) after a six minute runabout with submaximal effort (heart rate $>190$ beats/ min). Heart rate was monitored continuously with a Polar Electro OY (Finland). The test was performed indoors to avoid confounding by weather conditions. PEF was measured using the Mini-Wright spirometer of Clement Clarke Ltd (UK). At least five measurements were taken before the exercise and three measurements 5 and 10 minutes after the exercise, until a minimum of two values differing by less than $5 \%$ were obtained. At each time we used the highest value. A reduction of the PEF of $10 \%$ or more (PEF10) at 5 or 10 minutes post-exercise was considered a significant EIB. Total asthma prevalence was then calculated as the prevalence of children 
positive in the PEF10 test plus the prevalence of children negative in this test, but with medication for asthma reported in the questionnaire. To increase the specificity of the screening, we also calculated the prevalence of children with a postexercise reduction of PEF of $15 \%$ or more (PEF15). Information on the pool attendance of children was provided by the school directors. As in the first study, pool attendance was compulsory in all these schools, children being exempted only on the presentation of a medical certificate. All pools were chlorinated and subjected to the same water quality standards as in the first study.

\section{Determination of lung specific proteins}

Clara cell protein was determined by a latex immunoassay. ${ }^{18}$ Concentrations of surfactant associated proteins A and B were determined by ELISA (enzyme linked immunosorbent assay). ${ }^{19}{ }^{20}$ Serum IgE was measured by a kit in the Immunlite kit (DPC, USA). Cystatin C, a small sized protein like CC16 and SP-B, was determined in serum by latex immunoassay to detect possible variations in glomerular filtration, a potential confounder for serum concentrations of these proteins. ${ }^{21}$

\section{Statistics}

The statistical package SAS/STAT, version 6, 4th edition (SAS Institute Inc., Cary, NC, 1989) was used for all analyses. In the study of chronic effects on lung epithelium, concentrations of $\operatorname{IgE}$ and lung specific proteins in serum were normalised by log transformation. Factors influencing serum levels of these proteins in the chronic study were identified by stepwise multiple regression analysis by testing the following independent variables: age, gender (0, boy; 1 , girl), BMI, ethnic origin $(0$, white; 1 non-white), area of residence ( 0 , rural; 1 , urban), housing density (persons/room), swimming pool attendance (hours/week $\times$ years of school swimming), ETS, presence of mould on the walls of the sleeping room, house with doubleglazed windows, gas stove, and sporting activity other than swimming (scored 0 for the absence and 1 for the presence).

Variables age and BMI were centred, and to diagnose collinearity between independent variables staying in the model, eigenvalues and condition numbers were calculated: none indicated the existence of collinearity problems according the Belsley et al rule. ${ }^{22}$ Independent variables were entered in the model at $p=0.25$ and kept in the model at $p=0.10$. After adjustment for covariates, a dose-effect analysis was performed by dividing the children in quartiles of increasing pool attendance. Differences between quartiles were assessed by analysis of variance(ANOVA) followed by Dunett's multiple comparison test. Adjustment was made on the absence of the confounder or of the mean value of the parameter for the whole group. Associations between proteins in serum (IgE and lung specific proteins) were assessed by calculating Pearson's correlation coefficient. Acute effects of indoor pool chlorination products on lung proteins and cystatin $\mathrm{C}$ in serum were assessed by Wilcoxon's test.

In the asthma survey, Pearson's correlation coefficients were calculated to assess associations between asthma indicators and possible asthma determinants including age, sex, ethnic origin (white/non-white), socioeconomic status, exposure to pets or ETS, and cumulated attendance of the school pool. These variables were grouped by school using the prevalences and mean values observed in the 15 different schools. Cumulated pool attendance was estimated by multiplying the time spent in pool water (20 to 30 minutes) by the weekly frequency of attendance (1, weekly; 0.5, fortnightly; and 0.25 , monthly) and the number of years of attending the school pool. To detect possible age related differences in the susceptibility and/or exposure of children to chlorination products, we calculated indices of cumulated pool attendance over increasing periods extending from kindergarten (children 5-6 years old) until the last grade of primary school attained prior to the

\section{Table 1 Characteristics of children}

\begin{tabular}{ll}
\hline Boys/girls & $116 / 110$ \\
Age (years) & $10.0 \pm 0.9(8-12)$ \\
BMI (kg/m $\left.{ }^{2}\right)$ & $18.2(10.7-33.8)$ \\
Urban/rural & $79 / 147$ \\
White/non-white & $168 / 58$ \\
Sporting practice (other than swimming) & $129(57 \%)$ \\
Swimming pool attendance & \\
$n$ & $204(90.2 \%)$ \\
hours/week $\times$ years & $1.88(0.55-6.42)$ \\
Home environment & \\
$\quad$ Housing density (persons/room) & $0.53(0.19-5)$ \\
Parental smoking & $109(48.2 \%)$ \\
Pets & $116(51.3 \%)$ \\
Mould on bedroom walls & $16(7.1 \%)$ \\
House with double-glazed windows & $162(71.7 \%)$ \\
\hline
\end{tabular}

study. Adjustment for a pool hall height of $10 \mathrm{~m}$ was done by dividing the cumulated attendance indices by the pool hall height, then multiplying the indices by 10 . These indices were multiplied by the proportion of children exposed to pets and again by the proportion of children exposed to ETS in order to evaluate the combined influence of these factors. The probability of developing asthma or of being positive in the EIB test (PEF10 or PEF15) as a function of pool attendance was calculated by logistic regression analysis, in which level of statistical significance was set at $p=0.05$. With the exception of the latter test, we give $\mathrm{p}$ values when below 0.1 . Results are presented as geometric mean (range) or arithmetic mean (SD).

\section{RESULTS}

\section{Chronic effects on lung epithelium}

The study population included 226 children ( 116 boys and 110 girls), with a mean age of 10.0 years (table 1). Cumulated school pool attendance varied from 0.55 or less to 6.42 hours/ week $\times$ years. This almost tenfold variation was the result of differences in both the time spent in the pool water (30 to 60 minutes) and the grade when children started to regularly attend the school pool. Mean concentrations of lung specific proteins in the serum of children were as follows: CC16, 7.08 $\mu \mathrm{g} / \mathrm{l} \quad(2.35-18.7, \mathrm{n}=224) ; \mathrm{SP}-\mathrm{B}, 2016 \mu \mathrm{g} / \mathrm{l}$ (1020-4360, $\mathrm{n}=226)$ and SP-A, $310 \mu \mathrm{g} / \mathrm{l}(110-683, \mathrm{n}=224)$. Serum IgE averaged $62.2 \mathrm{UI} / \mathrm{l}(0.9-1980, \mathrm{n}=220)$.

Table 2 Factors influencing the serum concentrations of lung specific proteins and $\lg E$ in children

\begin{tabular}{|c|c|c|c|}
\hline & Partial $r^{2}$ & $\begin{array}{l}\text { Regression } \\
\text { coefficient }\end{array}$ & $\mathrm{p}$ value \\
\hline \multicolumn{4}{|l|}{ Surfactant associated protein B ( $\mu \mathrm{g} / \mathrm{l})$} \\
\hline Swimming pool attendance & 0.119 & 0.063 & 0.0001 \\
\hline Housing density & 0.037 & 0.178 & 0.0032 \\
\hline Gender & 0.033 & -0.073 & 0.0035 \\
\hline Mould on bedroom walls & 0.032 & -0.115 & 0.0049 \\
\hline Sport practice (other than swimming) & 0.020 & -0.047 & 0.021 \\
\hline Model & 0.241 & & \\
\hline \multicolumn{4}{|l|}{ Surfactant associated protein A ( $\mu \mathrm{g} / \mathrm{l})$} \\
\hline Age & 0.059 & 0.029 & 0.0004 \\
\hline Swimming pool attendance & 0.033 & 0.043 & 0.0063 \\
\hline Urban/rural area & 0.026 & 0.056 & 0.015 \\
\hline Model & 0.118 & & \\
\hline \multicolumn{4}{|l|}{ Clara cell protein $(\mu \mathrm{g} / \mathrm{l})$} \\
\hline White/non-white & 0.052 & -0.079 & 0.0009 \\
\hline House with double-glazed windows & 0.017 & -0.060 & 0.050 \\
\hline Swimming pool attendance & 0.016 & 0.024 & 0.061 \\
\hline Model & 0.085 & & \\
\hline \multicolumn{4}{|l|}{ Immunoglobulin $\mathrm{E}$ (UI/I) } \\
\hline Gender & 0.021 & -0.160 & 0.047 \\
\hline
\end{tabular}



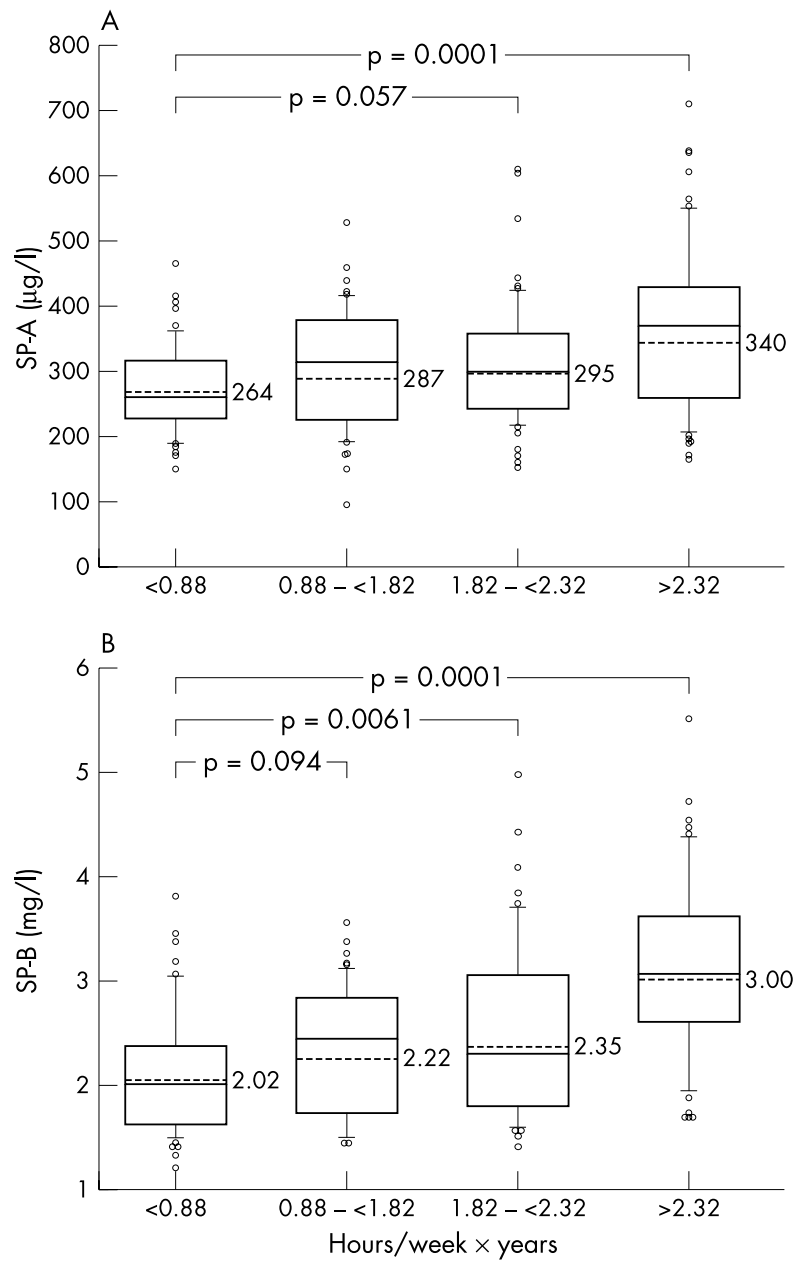

Figure 1 Concentrations of SP-A (A) and SP-B (B) in the serum of schoolchildren according to quartiles of swimming pool attendance. Box plot presentation. The figures correspond to the geometric means. Values are adjusted for other covariates listed in table 2.

Determinants of the concentrations of $\operatorname{IgE}$ and lung proteins in serum identified by multiple regression analysis are shown in table 2 . Of the 12 independent variables tested, nine emerged as statistically significant predictors. Both serum SP-B and IgE were lower in girls than boys, SP-A increased with age, and CC16 was lower in non-white children. Some variables associated with air quality predicted serum SP-B (increasing with housing density and decreasing with presence of mould on bedroom walls), serum SP-A (higher in urban area), and serum CCl6 (lower in poorly ventilated houses with double-glazed windows). Regular sporting activity other than swimming was associated with lower serum SP-B.

The independent variable most consistently influencing the concentrations of the three lung proteins in the serum of children was the cumulated attendance at the school pool. These associations were systematically positive, showing that regular pool attendance increases the permeability of the lung epithelial barrier to these proteins. They persisted when children living in Brussels $(n=79)$ and in the rural area $(n=147)$ were analysed separately ( $p<0.01$, results not shown). The association was remarkably strong with SP-B since pool attendance explained $11.9 \%$ of the variance of this lung protein in serum, a contribution alone equivalent to that of all other determinants. Even though pool attendance contributed less to the variances of serum SP-A and CCl6, the influence of pool attendance on these lung markers remained predominant compared to that of other sources of air pollution, such as ETS
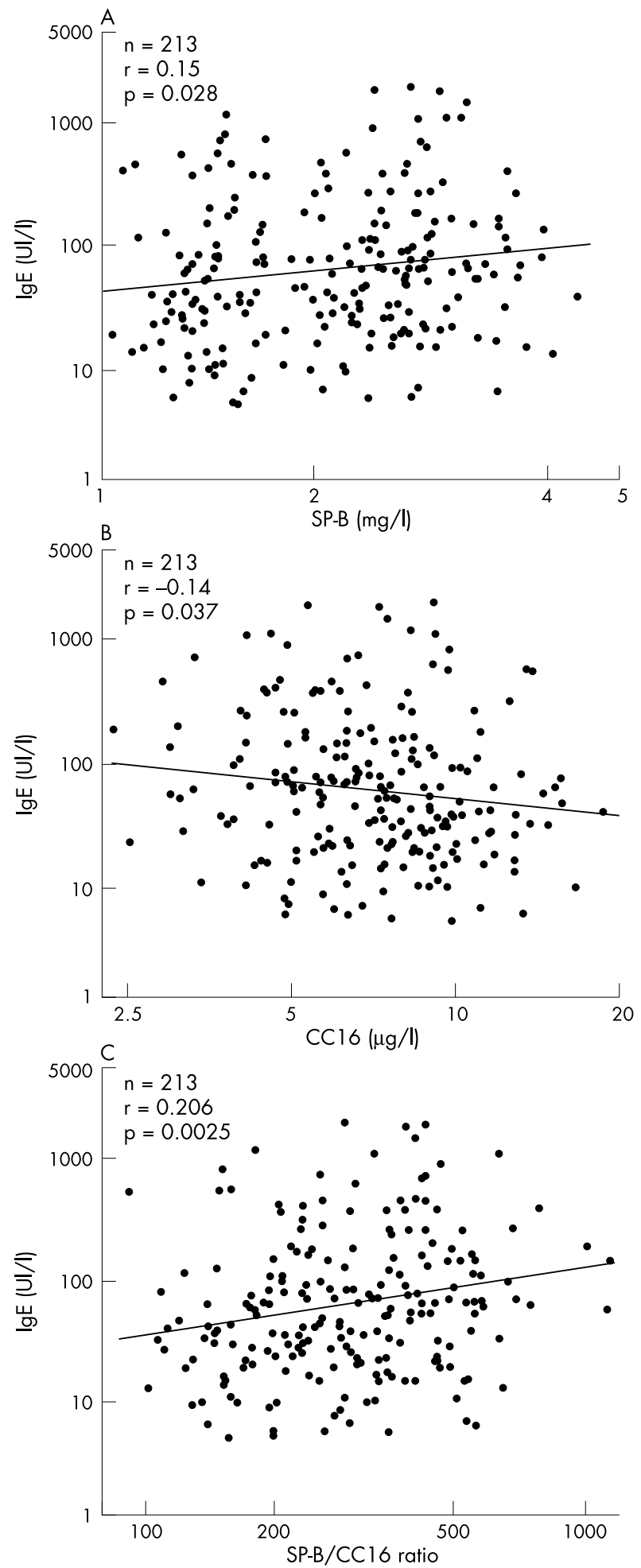

Figure 2 Correlations between $\lg E$ and SP-B (A), CCl6 (B), and the SP-B/CC16 ratio $(C)$ in serum of schoolchildren.

or gas stoves, which did not emerge as significant predictors of lung epithelium permeability.

In order to examine dose-effect relations, we classified the children in quartiles of increasing pool attendance and after adjustment for other covariates, we compared the mean values of lung proteins in serum by ANOVA. The concentrations of serum SP-B and SP-A showed an almost continuous exposure trend, with significant rises over the first quartile occurring from the second quartile (SP-B) and third quartile (SP-A) 
onwards (fig 1). This dose dependency was apparent not only in the mean values of these proteins, but also in the prevalence of increased values which, above a certain level (for example, SP-B $>4 \mathrm{mg} / \mathrm{l}$ and SP-A $>0.5 \mathrm{mg} / \mathrm{l}$ ), were all found in the children with the highest pool attendance frequencies (third and fourth quartiles). No clear dose-effect relation was found for serum CCl6 (ANOVA, $p=0.07$ ). The concentration of serum CC16 was significantly decreased in the second quartile compared to the first; the protein then increased significantly in a dose dependent manner in the third and fourth quartiles compared to the second (results not shown).

The concentrations of SP-A and SP-B in serum were significantly correlated ( $r=0.406, \mathrm{p}=0.0001)$, but these surfactant proteins were not correlated with serum CCl6. Serum levels of pneumoproteins were also not different between children without respiratory symptoms and those reporting recurrent respiratory symptoms during the past 12 months (prevalence of recurrent symptoms during the past 12 months: night cough, 25.7\%; wheezing, $18.1 \%$; shortness of breath, $20.8 \%$; phlegm, 7.5\%; chest tightness, $14.1 \%)$. Serum IgE was not significantly correlated with serum SP-A $(r=0.103, \mathrm{p}=0.13)$, but positively correlated with serum SP-B and negatively with serum CCl6 (fig 2). To integrate these opposite influences of increased alveolo-capillary permeability and damage to Clara cells, we calculated the SP-B/CC16 ratio. An even more significant correlation was found between serum IgE and this index, normalising the permeability of the epithelial barrier for levels of the antioxidant protein, $\mathrm{CCl} 6$.

\section{Acute effects on the lung epithelium}

Acute effects of chlorination products on the lung epithelium were studied in children and adults attending for two hours an indoor chlorinated pool (fig 3). The mean concentration of $\mathrm{NCl}_{3}$ during the experiment was $0.490 \mathrm{mg} / \mathrm{m}^{3}$. Most volunteers were regular swimmers, explaining why some of them had already increased values of surfactant associated proteins in serum before exposure (the two highest values of SP-B were found in two children who were regular swimmers since they were babies). Exposure to chlorination byproducts in the pool caused changes in the serum concentrations of lung proteins which were almost identical to those found in the chronic study. The concentrations of SP-A and SP-B and the $\mathrm{SP}-\mathrm{B} / \mathrm{CC} 16$ ratio in serum increased significantly in both children and adults. In the latter, the increases were already statistically significant after a one hour exposure without swimming, thus excluding a confounding by exercise. In children, as in the chronic study, serum CC16 did not show a consistent exposure-response relation, decreasing or increasing depending on the subject. In adults, by contrast, the response of serum CCl6 was clearly biphasic, with a significant decrease after one hour and a reversal towards normal one hour later.

The concentration of IgE in serum was unaffected by pool attendance (results not shown); as in the chronic study serum IgE was negatively correlated with serum CCl6 $(r=-0.44$, $\mathrm{p}=0.018$ ) and positively with the lung epithelium permeability as assessed by serum SP-B $(r=0.36, \mathrm{p}=0.062)$ or the serum SP-B/CC16 ratio $(r=0.53, \mathrm{p}=0.0035)$ (correlations calculated with pre-exposure values, $\mathrm{n}=29$ ).

\section{Relation between pool attendance and asthma prevalence}

Table 3 shows the characteristics of the children examined in the 15 primary schools and their pool attendance. The
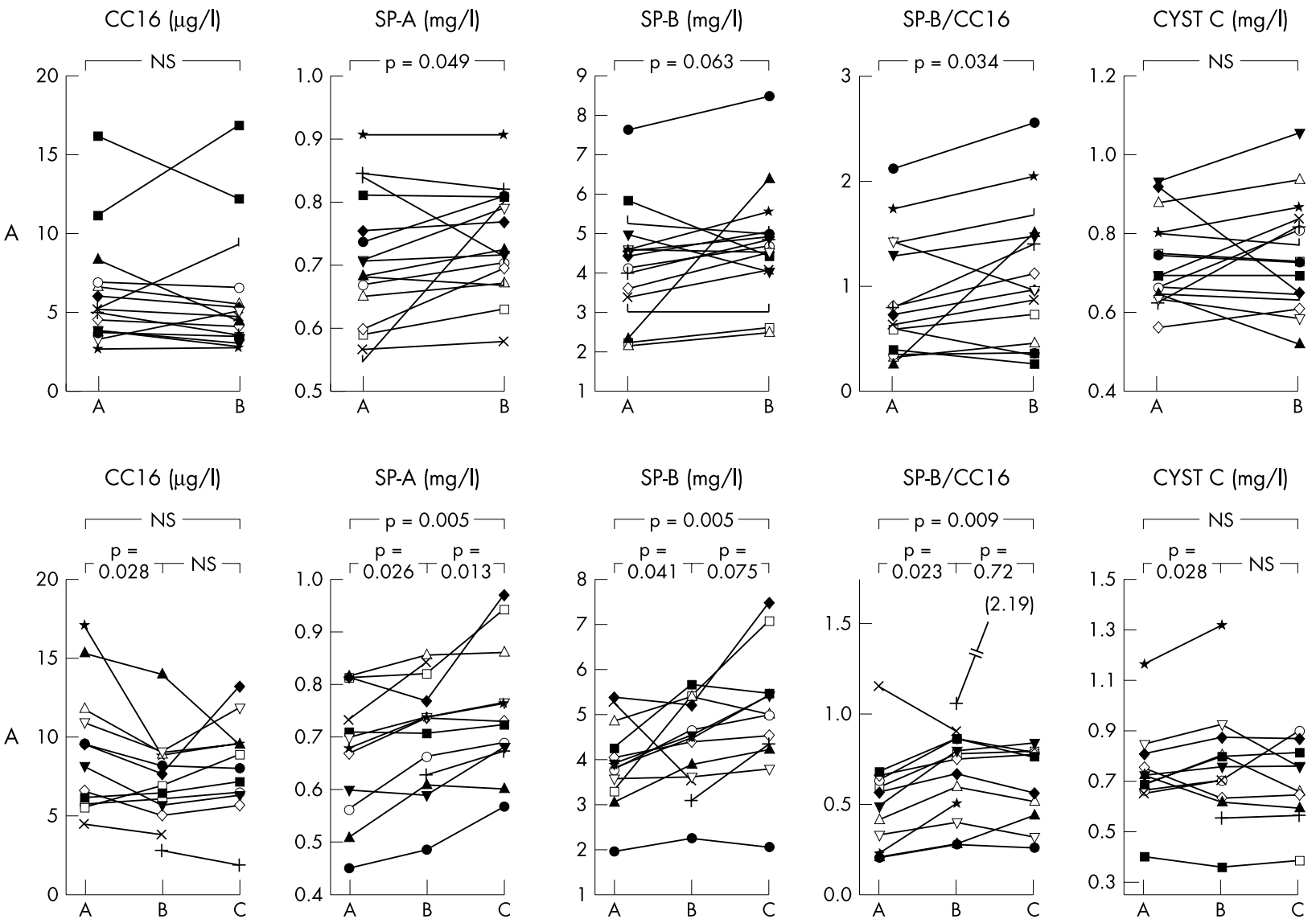

Figure 3 Concentrations of CC16, SP-A, SP-B, CYST C, and the SP-B/CC16 ratio in the serum of 16 children (A) and 13 adults (B) attending an indoor chlorinated pool. Children: A, before entering the pool; B, two hours after playing in the pool. Adults: A, before entering the pool; B after one hour stay in the pool without swimming; $\mathrm{C}$, one hour later after a 15-30 minute swimming session. $\mathrm{Mean}^{\mathrm{NCl}} \mathrm{C}_{3}$ concentration in pool air during the experiment was $0.490 \mathrm{mg} / \mathrm{m}^{3}$. 
Table 3 Characteristics and pool attendance of children from 15 different primary schools in Brussels

\begin{tabular}{|c|c|c|c|c|c|c|c|c|c|c|c|c|}
\hline \multirow[b]{2}{*}{ School no. } & \multirow[b]{2}{*}{$\mathrm{n}$} & \multirow[b]{2}{*}{ Age (years) } & \multirow[b]{2}{*}{$\begin{array}{l}\text { Sex } \\
\text { ratio }\end{array}$} & \multirow[b]{2}{*}{$\begin{array}{l}\text { White } \\
(\%)\end{array}$} & \multirow[b]{2}{*}{$\begin{array}{l}\text { Pets } \\
(\%)\end{array}$} & \multirow[b]{2}{*}{$\begin{array}{l}\text { ETS } \\
(\%)\end{array}$} & \multicolumn{2}{|c|}{ Pool attendance } & \multirow[b]{2}{*}{$\begin{array}{l}\text { Pool height } \\
\text { (m) }\end{array}$} & \multirow[b]{2}{*}{$\begin{array}{l}\text { PEF15 } \\
(\%)\end{array}$} & \multirow[b]{2}{*}{$\begin{array}{l}\text { PEF10 } \\
(\%)\end{array}$} & \multirow[b]{2}{*}{$\begin{array}{l}\text { Total asthmo } \\
(\%)\end{array}$} \\
\hline & & & & & & & Start & Min/wk & & & & \\
\hline 1 & 146 & $10.1(7-13)$ & 0.81 & 25 & 34.0 & 53.4 & k & 15 & 11 & 6.16 & 10.96 & 19.58 \\
\hline 2 & 75 & 10.5 (9-14) & 1.21 & 40 & 33.0 & 50.7 & pl & 15 & 11 & 2.66 & 2.67 & 11.11 \\
\hline 3 & 50 & 10.5 (9-14) & 1.00 & 60 & 50.0 & 60.0 & $\mathrm{k}$ & 12.5 & 11 & 0 & 2.00 & 8.00 \\
\hline 4 & 88 & $10.6(9-13)$ & 0.80 & 99 & 25.0 & 42.0 & k & 15 & 11 & 7.95 & 11.36 & 12.5 \\
\hline 5 & 49 & $10.1(8-12)$ & 1.33 & 40 & 28.6 & 34.7 & k & $15^{*}$ & 11 & 6.12 & 10.2 & 18.37 \\
\hline 6 & 109 & 10.9 (9-13) & 1.02 & 10 & 40.0 & 55.0 & k & 20 & 11 & 3.66 & 11.0 & 14.81 \\
\hline 7 & 171 & $10.3(8-13)$ & 1.09 & 90 & 45.6 & 56.7 & p5 & 30 & 11 & 2.92 & 6.43 & 14.04 \\
\hline 8 & 97 & $10.8(9-13)$ & 1.18 & 74 & 47.4 & 48.5 & $\mathrm{k}$ & $15 \dagger$ & 7 & 6.2 & 6.36 & 12.77 \\
\hline 9 & 84 & 10.5 (9-14) & 1.33 & 90 & 71.0 & 56.0 & k & $30 \ddagger$ & 6 & 9.5 & 26.0 & 30.49 \\
\hline 10 & 182 & $10.3(9-13)$ & 1.25 & 88 & 61.5 & 51.1 & pl & $30^{+}$ & 8 & 0.55 & 2.19 & 8.57 \\
\hline 11 & 110 & $10.6(9-13)$ & 1.08 & 10 & 75.4 & 34.0 & p2 & 15 & 8 & 0.91 & 2.72 & 5.45 \\
\hline 12 & 119 & $10.6(8-13)$ & 0.92 & 25 & 38.7 & 45.4 & k & 15 & 8 & 1.68 & 5.88 & 13.45 \\
\hline 13 & 80 & $11.0(8-14)$ & 1.19 & 40 & 37.5 & 32.0 & k & 30 & 8 & 7.5 & 11.26 & 14.10 \\
\hline 14 & 228 & $9.1(7-12)$ & 0.98 & 80 & 56.1 & 50.9 & k & 30 & 15 & 7.02 & 12.7 & 20.10 \\
\hline 15 & 293 & $8.9(6-12)$ & 1.26 & 99 & 53.9 & 42.7 & k & 15 & 15 & 3.41 & 7.2 & 9.63 \\
\hline
\end{tabular}

The letters give the weekly duration of pool attendance during kindergarten when the latter was different from that in later grades: * 30 min; $† 6$ min; $¥ 15$ min; PEF 10, prevalence of children with a $10 \%$ post-exercise reduction of peak expiratory flow; PEF 15, prevalence of children with a $15 \%$ post-exercise reduction of peak expiratory flow. Total asthma is the sum of the prevalence of PEF 10 plus the prevalence of EIB negative children but treated for asthma. $k$, kindergarten (ages 5-6 years); $\mathrm{pl}$ to $\mathrm{p} 5$, first to fifth grade of primary school.

prevalence of children with EIB showed a very large variation between schools, from $2 \%$ to $26 \%$ (mean $8.9 \%$ ) for PEF 10 and from $0 \%$ to $7.95 \%$ (mean $4.42 \%$ ) for PEF15. Total asthma prevalence varied between $5.5 \%$ and $30.5 \%$ (mean $14.2 \%$ ). Prevalences of respiratory symptoms, and in particular of wheezing (mean 15.5\%, range 3.6-29.9\%,) were not correlated with the prevalences of EIB or of total asthma, or with predictors listed in table 3 (results not shown). No statistically significant correlation was found between the prevalences of EIB and total asthma and age, sex, the proportion of children exposed to pets or ETS, the proportion of whites/non-whites, or the socioeconomic status (all p values were above 0.3 ).

The only variable to be significantly correlated with these asthma indicators was the cumulated pool attendance. Confounding by age is excluded since pool attendance cumulated over any period of time showed no correlation with age (all p values were above 0.3 ). As illustrated in fig 4, when pool attendance indices were unadjusted for the height of pool hall, associations with total asthma prevalence were statistically significant at $\mathrm{p}$ levels below 0.05 for the pool attendance cumulated from the kindergarten until 1st or 2nd grade of primary school and at p levels below 0.1 for pool attendance cumulated during kindergarten and until later grades. Adjustment for the height of the pool hall used as surrogate estimate of the pool air quality increased the strength of these associations which were all significant with p levels below 0.05. More remarkably, associations between asthma prevalence and pool attendance cumulated over any period of time were substantially strengthened, with p levels falling below 0.01 , when the pool attendance indices were successively adjusted for exposure to pets and ETS.

For all these pool attendance indices, associations between asthma prevalence and pool attendance were strongest when the children were the youngest and presumably thus the most exposed to chlorination products. Figure 5 illustrates the correlations between total asthma and the pool attendance indices calculated during kindergarten and 1st grade of primary school. Similar patterns of statistically significant associations were observed with the prevalences of PEF10 and PEF15. The correlations between PEF10 prevalence and pool attendance also peaked when attendance was cumulated during the two first grades, with $r^{2}$ increasing from $0.31(\mathrm{p}=0.03)$ to 0.484 $(\mathrm{p}=0.004), 0.64(\mathrm{p}=0.0003)$, and $0.707(\mathrm{p}=0.0001)$ after successive adjustment for pool hall height, exposure to pets, and exposure to ETS, respectively.
The correlations between prevalence of PEF15 and pool attendance were also the strongest with attendance cumulated during kindergarten and the first grade of primary schools $\left(r^{2}=0.358, \mathrm{p}=0.018\right)$ and showed a similar pattern of increase after adjustment for the height of pool hall $\left(r^{2}=0.42, \mathrm{p}=0.031\right)$ and exposure to pets $\left(r^{2}=0.44\right.$, $p=0.0066)$. Correlations with PEF15 were however not strengthened by the adjustment for ETS exposure $\left(r^{2}=0.37\right.$,

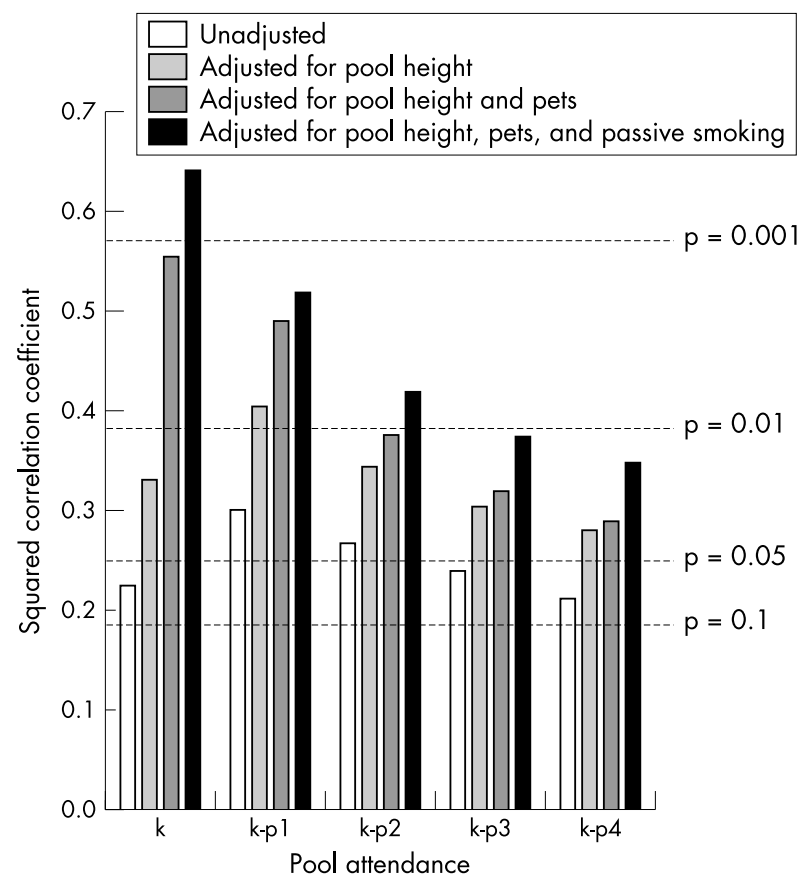

Figure 4 Square correlation coefficients between total asthma prevalence and cumulated pool attendance in 15 primary schools in Brussels. The pool attendance indices, expressed in $\mathrm{min} /$ week $\times$ years, were calculated for each school over increasing periods of time, from the kindergarten up to the last grade of primary school (p4). Correlations were calculated with unadjusted index, then with indices successively adjusted to a pool hall height of 10 metres, for exposure to pets or to ETS, and for exposure to both pets and ETS. Adjustment for these variables was done by multiplying the indices by the proportions of exposed children in the different schools. The number of children in the schools and the data used to calculate pool attendance indices are given in table 3 . 

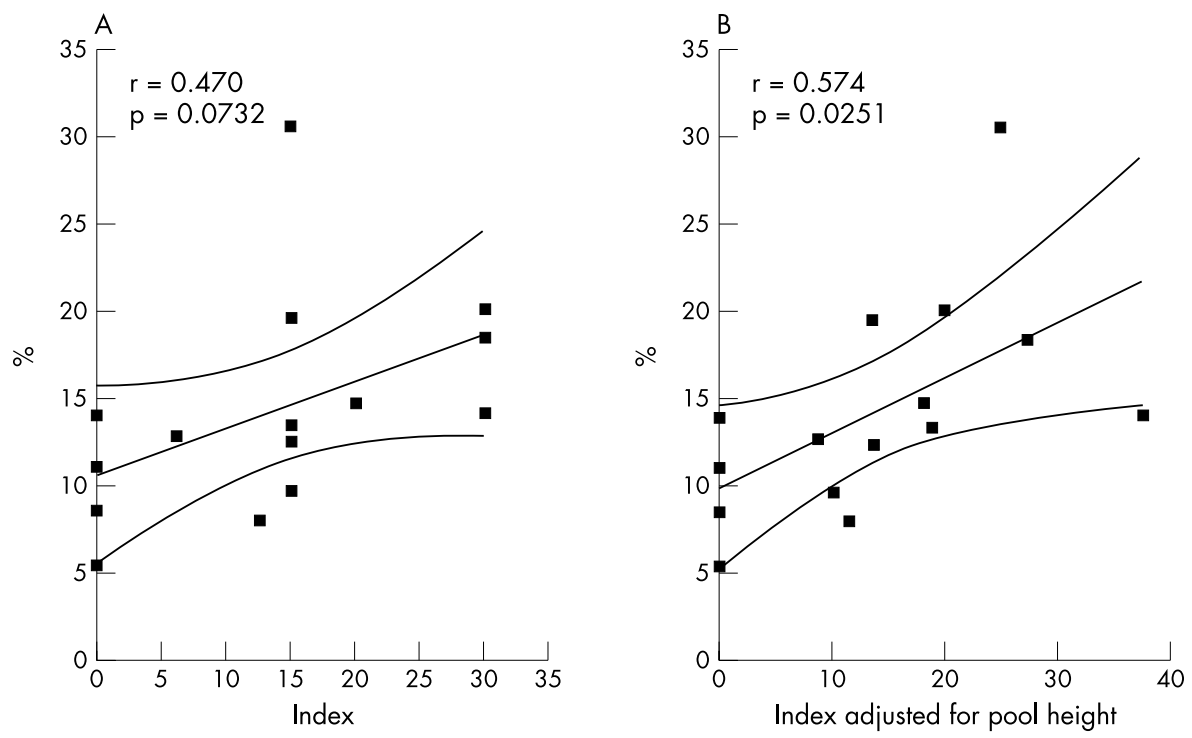

Figure 5 Correlations between total asthma prevalence rates and cumulated pool attendance during the kindergarten and 1 st grade of primary school. The pool attendance indices, expressed in $\mathrm{min} /$ week $\times$ years, were unadjusted $(A)$, adjusted to a pool hall height of 10 metres (B), adjusted for exposure to pets $(C)$, or for exposure to both pets and ETS (D). Adjustment for these variables was as explained in fig 4.
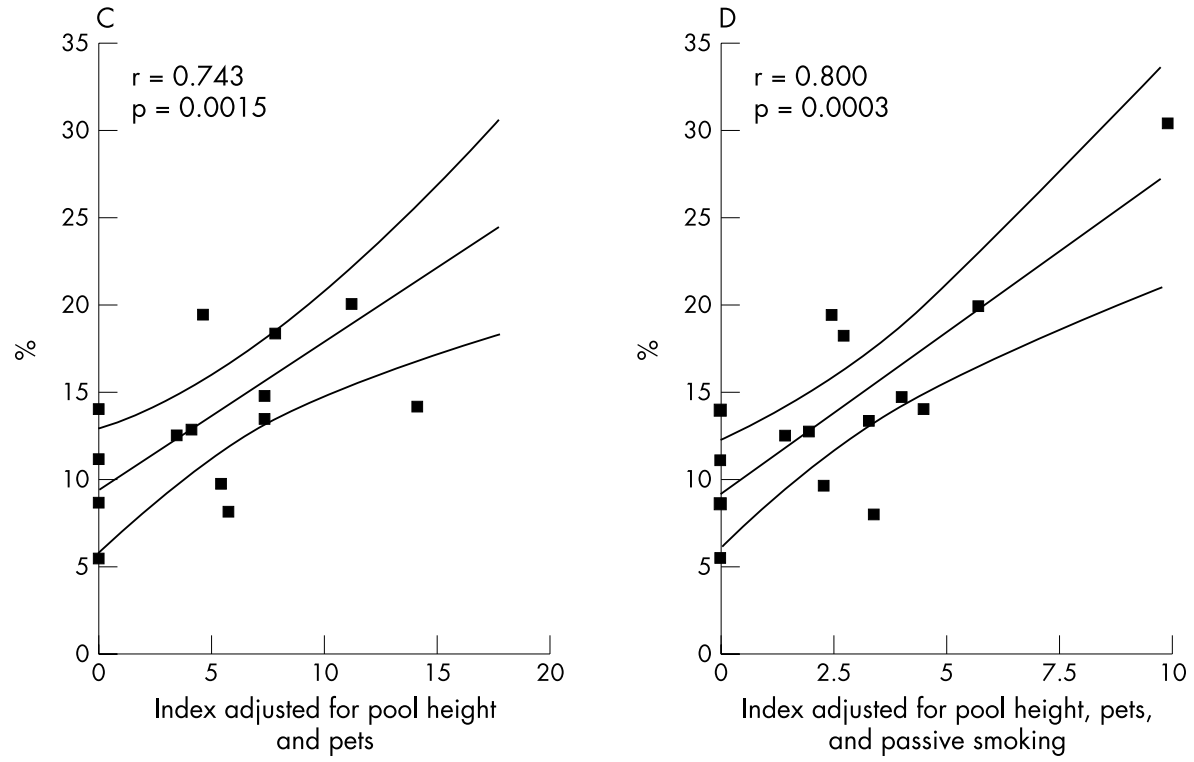

$\mathrm{p}=0.016)$. The probability of developing asthma, or of being positive in the EIB test (PEF10 or PEF15) as a function of pool attendance was assessed by logistic regression analysis. Figure 6 illustrates the modelling of data and the odds ratio when these three asthma indicators were best associated with cumulated pool attendance-that is, during kindergarten and lst grade of primary school (total asthma), and during kindergarten only (PEF10 and PEF15), respectively.

\section{DISCUSSION}

This study is the first to report evidence that exposure to chlorination products in indoor swimming pools may cause adverse effects on the lung epithelium of recreational swimmers. Toxic effects on the lung epithelium were detected by measuring the intravascular leakage of three lung specific proteins secreted in distal airspaces: CC16 secreted by Clara cells in airways and the surfactant associated proteins A and B secreted mainly by type 2 pneumocytes in alveolar spaces. In the chronic study, the increase in serum SP-A and SP-B was remarkably dose dependent, whereas the rise in serum CC16 was less so, probably because the serum level of this protein has a double meaning, reflecting the epithelial permeability as well as the integrity of Clara cells. It is thus possible that the increased intravascular leakage of this protein caused by exposure to chlorination products is partly masked by a concomitant chronic damage to Clara cells as this occurs in smokers. ${ }^{13}{ }^{14}$ It is noteworthy that the increase of serum SP-B in children with the highest pool attendance (4th quartile in fig 1) is about of the same magnitude as that which we recently observed in current smokers, indicating that these changes are far from being negligible. In smokers, the increase of serum SP-B was also remarkably dose dependent, with a very significant correlation with the smoking history expressed in pack-years. ${ }^{23}$ Relations between serum pneumoproteins and pool attendance remained statistically significant when the data from the children living in the urban or rural areas were examined separately. For SP-B, the positive association with pool attendance was further strengthened when extracurricular pool attendance was added to the model (total variance explained by pool attendance increasing to $13 \%$ for SP-B). However, because this private attendance was not quantified by the questionnaire, we did not include these data in the final analysis. Our findings were not abrogated by other sporting activity, which was only significant with regard to serum SP-B, but exerting an influence opposite to that of swimming pool attendance.

All these findings were reproduced during short term exposure of children and adults in an indoor chlorinated 

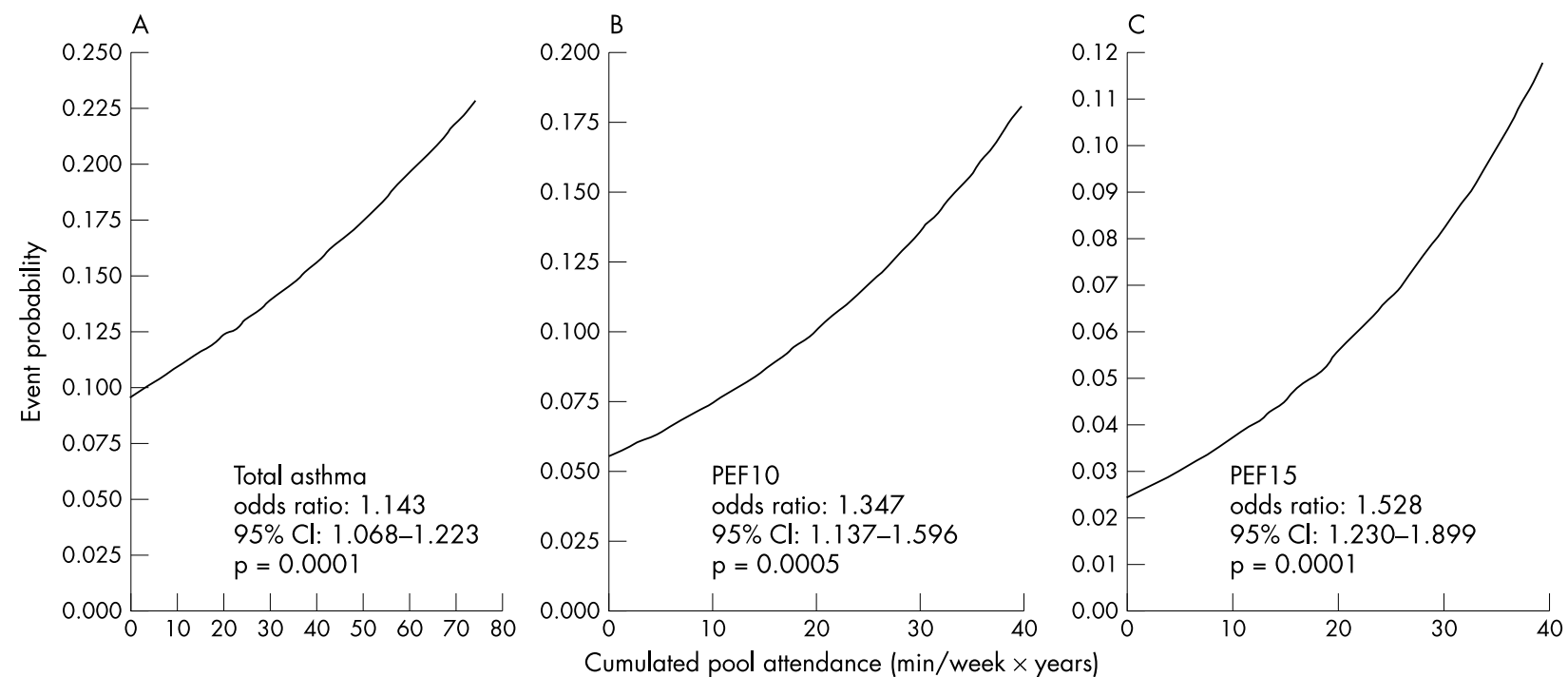

Figure 6 Logistic regression analysis of the probability of developing asthma or a post-exercise reduction of PEF of 10\% or more (PEF 10) or of $15 \%$ or more (PEF 15) according to cumulated pool attendance during kindergarten and first grade of primary school. (A) Total asthma, defined as prevalence of PEF 10 plus prevalence of children with no EIB but treated for asthma; pool attendance cumulated during kindergarten and 1 st grade of primary school. (B) Prevalence of PEF10 and pool attendance during kindergarten only. (C) Prevalence of PEF 15 and pool attendance during kindergarten only. Analysis based on data in table 3 and the total cohort $(n=1881)$.

pool. The pattern of changes was almost identical to that found in the chronic study with an exposure dependent increase of serum SP-A and SP-B and an equivocal response of CC16. Confounding by exercise was excluded, since in adults these changes were already statistically significant after one hour exposure without swimming. The hypothesis of an exercise induced altered renal clearance of the small sized lung proteins such as CC16 or SP-B is also refuted by the lack of change in serum cystatin C. The acute increase of lung epithelium permeability induced by $\mathrm{NCl}_{3}$ was evidenced when using SP-A and SP-B as markers. Since these two proteins are mainly produced by the alveolar epithelium, in contrast to CC 16 which is secreted exclusively in airways, ${ }^{11}{ }^{15}$ this suggests that, at least at levels in indoor pools, $\mathrm{NCl}_{3}$ causes short term permeability changes, preferentially affecting the deep lung. These results are fully consistent with the physical properties of this gas which, because of its very low solubility in water, is not retained by the upper respiratory tract and thus carried over in the deep lung where it may exert its toxicity. Of note also, in both the chronic and the acute study, the increase of serum SP-B was more pronounced than that of SP-A. This higher sensitivity of SP-B compared to SP-A, also observed in smokers, ${ }^{23}$ can be explained by the smaller size of SP-B and its hydrophobic nature, two features facilitating its leakage across the disrupted lung epithelial barrier. ${ }^{11}$

Although new, our findings are not really surprising when one considers the concentrations and toxicity of chlorination products in an indoor pool. Swimmers are mainly exposed to chlorine compounds when actively inhaling air just above the water's surface. The chemical composition of this air is extremely complex and depends on a number of physicochemical variables related to the chlorine dosing, bathing load, mode of swimming, air temperature, water turbulence, and ventilation of the hall. ${ }^{1}$ The most powerful and concentrated oxidants in this mixture are $\mathrm{NCl}_{3}$ in the gaseous phase and hypochlorous acid and the mono- and dichloroamines in aerosols. In public pools, the concentrations of hypochlorous acid and chloramines in water usually vary between 0.2 and $1.5 \mathrm{mg} / \mathrm{l}$. Concentrations of $\mathrm{NCl}_{3}$ in air sampled $1.5 \mathrm{~m}$ above water surface fluctuate greatly with pool occupancy, ventilation, and bathers' hygiene. $\mathrm{NCl}_{3}$ levels in public pools are typically in the range $0.1-1 \mathrm{mg} / \mathrm{m}^{3}$ in air sampled $1.5 \mathrm{~m}$ above water's surface. ${ }^{3}$ Similar values $(0.14-0.8$ $\mathrm{mg} / \mathrm{m}^{3}$ ) were found in eight public pools in Brussels which were monitored to select a pool for the experiments on volunteers. Hypochlorous acid and chloramines are known to be powerful membrane penetrating oxidants reacting rapidly with the sulphhydryl groups of proteins in the cytoskeleton and extracellular matrix of the endothelial or epithelial barriers. In vitro studies have shown that both hypochlorous acid and chloramines are capable of disorganising the cytoskeleton, causing cell retraction, disruption of cellular junctions, and an almost immediate increase of endothelial or epithelial permeability. ${ }^{24}$ Similar changes occur during infection and inflammation when inflammatory cells possessing a myeloperoxidase activity release hypochlorous acid and chloramines, as part of their bactericidal function or to facilitate cell recruitment. ${ }^{26}{ }^{27}$ These effects are induced by concentrations of hypochlorous acid and monochloramine as low as $10 \mu \mathrm{M}(0.5$ $\mathrm{mg} / \mathrm{l}$ ), concentrations similar to those found in pool water. Hypochlorous acid and monochloramine have also been shown to rapidly increase the microvascular permeability of isolated rat lung at concentrations of $50 \mu \mathrm{M}(2.5 \mathrm{mg} / \mathrm{l}) .{ }^{27} \mathrm{Con}-$ centrations of this magnitude are quite conceivable within the epithelial lining fluid of a swimmer actively inhaling air of a poorly ventilated pool with accumulation of gases and even mist just above water. These experimental data, in agreement with our observations, thus indicate that levels of oxidants in the air or water of indoor swimming pools can be sufficiently high to affect the integrity of the lung epithelium.

Concerning the clinical significance of these effects, our attention was drawn in both the chronic and acute studies by the positive correlations emerging between lung epithelium markers and serum IgE which is presently regarded as the principal risk factor for the development of childhood asthma. $^{28}$ The concentration of serum $\operatorname{IgE}$ was indeed inversely related to that of serum CC16, an observation consistent with previous data suggesting that CC16 may be involved in the development of asthma. ${ }^{29}$ By contrast, serum IgE was positively correlated with lung hyperpermeability, as assessed by serum SP-B or SP-B/CC16, which are the markers showing the best exposure-response relations with pool attendance in both the chronic and the acute study. These observations suggest that the increased epithelial permeability caused by chlorination products might predispose children to the development of asthma. To test this hypothesis, we retrospectively analysed data from an asthma survey which was 
conducted between 1996 and 1999 on a cohort of 1881 children from 15 primary schools with kindergartens in Brussels. Asthma was screened by measuring the post-exercise fall in PEF, a reliable and frequently used indicator in field studies on asthma prevalence, especially in community groups with cultural and socioeconomic disparities. ${ }^{30-32}$ We calculated the prevalence of children with a $10 \%$ or more reduction of $\mathrm{PEF}$, a sensitive indicator that we completed with the prevalence of children negative in this test but taking medication for asthma as reported in the questionnaire. We also calculated the prevalence of children with a $15 \%$ reduction of PEF, a more specific and predictive indicator of clinical asthma. ${ }^{33}$ Indices of cumulated pool attendance were constructed to take into account the possible influence of age of the children and height of the pool hall, and to detect possible interactions with other risk factors, in particular exposure to pets and ETS. In the absence of historical data on levels of $\mathrm{NCl}_{3}$, the pool hall height was used as a surrogate estimate of the air quality inside the pool. Associations between all these pool attendance indices and the three indicators of asthma prevalence (total asthma, PEF10, and PEF 15) were the strongest when the children were the youngest, which is consistent with the early onset of childhood asthma and also with the fact that exposure levels of children to chlorination products presumably peak during swimming training. Adjustment for height of the pool hall reinforced associations between the three indicators of asthma and pool attendance, supporting the hypothesis of causality, since pool hall height can of course only influence air quality inside the pool. A very strong argument in favuor of causality comes from the synergistic action of exposure to pets and ETS, two well documented risk factors for asthma, which together considerably increase the strength of the associations, to levels largely above those usually observed in asthma epidemiology.

The hypothesis that exposure to chlorination products in indoor pools may promote the development of asthma may appear paradoxical since swimming in the hot and humid air of an indoor pool is recognised as having a low asthmatogenicity in comparison with other physical activities. However, no long term prospective study has been conducted to weigh the beneficial effects of swimming against the possible deleterious effects of excessive exposure to chlorination products. The few studies published on this topic tend, on the contrary, to support our hypothesis, since they report unusually high prevalences of asthma and bronchial hyperresponsiveness in elite swimmers compared to other athletes, a finding that the authors ascribe more to exposure to irritants than to a selection bias, because this activity is well tolerated by asthmatics. ${ }^{34}$ Case reports also sporadically appear relating the development or worsening of asthma to the irritant effects of chlorine based disinfectants. ${ }^{36-40}$ Our hypothesis is also consistent with the bulk of epidemiological data identifying exposure to irritants as a risk factor for the development of bronchial hyperactivity and asthma in children and in occupationally exposed populations. ${ }^{41}$ Exposure to chlorine based disinfectants has also been reported as a risk factor for atopic sensitisation and the development of asthma-like symptoms in pig farmers. ${ }^{42} \mathrm{~A}$ basic mechanism underlying all these associations could be a repeated or chronic disruption of the lung epithelial barrier facilitating the penetration of allergens in the lung, while entailing a loss of lung secretory proteins (for example, $\mathrm{CCl}$ ) as a result of their leakage across the epithelium or of epithelial damage. The hypothesis that lung hyperpermeability may increase the risk of asthma is supported by the observation that allergic sensitisation is facilitated in case of allergens with proteolytic activity, which allows them to degrade extracellular matrix proteins and to cross the airway epithelium more readily. ${ }^{43}{ }^{44}$

In conclusion, the present study indicates that there is a need to conduct epidemiological studies to verify if the increasing chlorinated pool attendance, especially by young children, could not be an important westernisation associated factor involved in the rising incidence of childhood asthma and allergic diseases in most industrialised countries. In the meantime, because of the lack of data on the potential health risks of chloramines and other chlorination products in indoor pools, ${ }^{145}$ the question needs to be raised as to whether it would not be prudent in the future to move towards non-chlorine based disinfectants, or at least to reinforce water and air quality control in indoor pools (bathers' hygiene, hall ventilation, water renewal, etc) in order to minimise exposure to these reactive chemicals.

\section{ACKNOWLEDGEMENTS}

This study has been supported by the Ministry of Environment of the Brussels-Capital Region and the European Union (HELIOS project). Alfred Bernard is Research Director of the National Fund for Scientific Research, Belgium. Sandra Higuet has been supported by a grant from AstraZeneca Belgium.

\section{Authors' affiliations}

A Bernard, S Carbonnelle, C de Burbure, J-P Buchet, $C$ Hermans, X Dumont, Industrial Toxicology Unit, Faculty of Medicine, Catholic University of Louvain, B-1200 Brussels, Belgium

O Michel, S Higuet, Clinic of Allergology and Respiratory Diseases, $\mathrm{St}$ Pierre University Hospital, Free University of Brussels, rue Haute 322,

B-1000 Brussels, Belgium

I Doyle, Departments of Human Physiology and Critical Care Medicine, School of Medicine, Flinders University, Adelaide, Australia

\section{REFERENCES}

1 WHO. Guidelines for safe recreational-water environments. Vol 2. Swimming pools, spas and similar recreational-water-environment. Geneva: World Health Organisation, 2000.

2 Jessen HJ. Chloramine concentration in the air of indoor baths. $Z$ Gesamte Hyg 1988;34:248-50

3 Hery M, Hecht G, Gerber JM, et al. Exposure to chloramines in the atmosphere of indoor swimming pools. Ann Occup Hyg 1995:39:437-9.

4 Massin N, Bohadana $A B$, Wild $P$, et al. Respiratory symptoms and bronchial responsiveness in lifeguards exposed to nitrogen trichloride in indoor swimming pools. Occup Environ Med 1998;55:258-63.

5 Gagnaire $F$, Azim S, Bonnet $P$, et al. Comparison of the sensory irritation response in mice to chlorine and nitrogen chloride. J Appl Toxicol 1994; 14:405-9.

6 Barbee SJ, Thackara JW, Rinehart WE. Acute inhalation toxicology of nitrogen trichloride. Am Ind Hyg Ass J 1983;44: 145-6.

7 Karnak I, TanyEl FC, Buyukpamukou N, et al. Pulmonary effects of household bleach ingestion in children. Clin Pediatr Phila 1996;35:471-2.

8 Tanen DA, Graeme KA, Raschke R. Severe lung injury after exposure to chloramine gas from household cleaners. N Engl J Med 1999:341:848-9.

9 Martinez TT, Long C. Explosion risk from swimming pool chlorinators and review of chlorine toxicity. J Toxicol Clin Toxicol 1995;33:349-54.

10 Hermans C, Bernard A. Pneumoproteinemia: a new perspective in the assessment of lung disorders. Eur Respir J 1998;11:801-3.

11 Hermans C, Bernard A. Lung epithelium-specific proteins. Characteristics and potential applications. State of the Art. Am J Respir Crit Care Med 1999; 159:646-78.

12 Broeckaert F, Arsalane K, Hermans C, et al. Lung epithelium damage at low levels of ambient ozone detected by serum Clara cell protein (CC16). Lancet 1999:353:900-1.

13 Bernard A, Roels H, Buchet JP, et al. Decrease of serum Clara cell protein in smokers. Lancet 1992;339:1620.

14 Shijubo N, Itoh Y, Yamagashi T, et al. Serum and Clara cell 10 kDa protein (CC10) levels and CC10-positive bronchiolar Clara cells are decreased in smokers. Eur Respir J 1997;10:1108-14.

15 Broeckaert F, Bernard A. Clara cell protein (CC 16): characteristics and perspectives as lung peripheral biomarker. Clin Exp Allergy 2000;30:469-75.

16 Burney PG, Laitinen LA, Perdrizet S, et al. Validity and repeatability of the IUATLD bronchial symptoms questionnaire: an international comparison. Eur Respir J 1989;2:940-5.

17 Ernst P, Demissie K, Joseph L, et al. Socio-economic status and indicator of asthma in children. Am J Respir Crit Care Med 1995;152:570-5.

18 Hermans C, Osman A, Nyberg Bl, et al. Determinants of Clara cell protein (CC 16) concentration in serum: a reassessment with two different immunoassays. Clin Chim Acta 1998;272:101-10.

19 Doyle IR, Nicholas TE, Bersten AD. Serum-surfactant protein-A (SP-A) levels in patients with acute cardiogenic pulmonary edema and adult respiratory distress syndrome. Am J Respir Crit Care Med $1995 ; 152: 307-17$ 
20 Doyle IR, Bersten AD, Nicholas AD. Surfactant proteins A and B are elevated in plasma of patients with acute respiratory failure. Am J Respir Crit Care Med 1997; 156:1217-29.

21 Newman DJ, Thakkar H, Edwards RG, et al. Serum cystatin C: a replacement for creatinine as marker of GFR. Kidney Int 1994:47:S20-1.

22 Belsley DA, Kuh E, Welsch RE. In: Regression diagnostics: identifying influential data and sources of collinearity. New York: John Wiley and Sons, Inc., 1980.

23 Robin M, Hermans C, Bernard A, et al. Serum levels of CC16, SP-A and SP-B reflect tobacco smoker exposure in asymptomatic subjects. Eur Respir J 2002;20: 1152-61.

24 Schraufstätter I, Browne K, Harris A, et al. Mechanisms of hypochlorite injury to target cells. J Clin Invest 1990;85:554-62.

25 Nakamura TY, Yamamoto I, Nishitani A, et al. Detachment of cultured cells from the substratum induced by the neutrophil-derived oxidant $\mathrm{NH} 2 \mathrm{Cl}$ : synergistic role of phosphotyrosine and intracellular $\mathrm{Ca} 2+$ concentration. J Biol Chem 1995;131:509-24.

26 Schuller-Levis G, Quinn MR, Wright C, et al. Taurine protects against oxidant-induced lung injury: possible mechanism(s) of action. Adv Exp Med Biol 1994;35:931-9.

27 Tatsumi T, Fliss $\mathrm{H}$. Hypochlorous acid and chloramines increases endothelial permeability: possible involvement of cellular zinc. Am J Physiol 1994;267:H1597-607.

28 Bates DV. Observations on asthma. Environ Health Perspect 1995; 103:243-7.

29 Laing I, Hermans C, Bernard A, et al. Association between plasma CC16 levels, the A38G polymorphism, and asthma. Am J Respir Crit Care Med 2000;161:124-7.

30 McFadden ER, Gilbert IA. Exercise-induced asthma. N Engl J Med 1994;330:1362-7.

31 Priftaniiji A, Strachan D, Burr $M$, et al. Asthma and allergy in Albania and the UK. Lancet 2001;358:1426-7.
32 Boezen HM, van der Zee S, Postma D, et al. Effects of air pollution on upper and lower respiratory symptoms and peak expiratory flow. Lancet 1999;353:874-8.

33 Jones A. Asymptomatic bronchial hyperreactivity and the development of asthma and other respiratory illness in children. Thorax 1994:49.757-61.

34 Helenius I, Rytila P, Metso T, et al. Respiratory symptoms bronchial responsiveness and cellular characteristics of induced sputum in elite swimmers. Allergy 1998;53:346-52.

35 Potts J. Factors associated with respiratory problems in swimmers. Sports Med 1996:21:256-61

36 Mustchin CP, Pickering CAC. "Coughing water": bronchial hyperactivity induced by swimming in a chlorinated pool. Thorax 1979;34:682-3.

37 Penny PT. Swimming pool wheezing. BM Clin Res Ed 1983;287:461-2.

38 Watt SJ. Wheezing in a commercial diver due to disinfectant. Undersea Biomed Res 1991;18:347-9.

39 Fjellbirkeland L, Gulsvik A, Walloe A. Swimming induced asthma. Tidsskr Nor Lazegeforen 1995;30:2051-3.

40 Deschamps D, Soler P, Rosengerg N, et al. Persistent asthma after inhalation of sodium hypochlorite and hydrochloric acid. Chest 1994:5: 1895-6.

41 Nelson HS. Allergen and irritant control: importance and implementation. Clin Cornerstone 1998;1:57-68.

42 Preller L, Doekes G, Heederik D, et al. Disinfectant use as a risk factor for atopic sensitization and symptoms consistent with asthma: an epidemiological study. Eur Respir J 1996:9:1407-13.

43 Ring PC, Wan H, Schou C, et al. The $18 \mathrm{kDa}$ form of cat allergen Felis domesticus 1 (Fel $d$ l) is associated with gelatin- and fibronectin-degrading activity. Clin Exp Allergy 2000;30: 1085-96.

44 Stewart G, Thompson P, McWilliam AS. Biochemical properties of aeroallergens: contributory factors in allergic sensitization? Pediatr Allergy Immunol 1993;4:163-72.

45 EPA. Chloramines. US Environmental Protection Agency, 1994

\section{$\mathrm{ECHO}$}

\section{Canadian lawyers argue for law reform on drink driving}

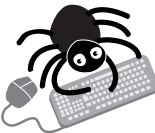

Please visit the Occupational and

Environmental website [www. occenvmed. com] for link to this full article.
D rink driving will remain the leading criminal cause of death and a leading cause of injury in Canada, unless the blood alcohol limit for driving under federal law is lowered to $0.05 \%$, Canadian lawyers argue .

Every year drink driving costs the country \$1.5-10bn. A federal law dating back to 1969 set the legal blood alcohol concentration (BAC) for driving at $0.08 \%$ - the $0.08 \%$ Criminal Code. In 1999 parliament rejected petitions for a 0.05 limit, for lack of supporting scientific evidence and expert agreement and for imagined enforcement difficulties.

Such arguments are ill founded, say the lawyers. A wealth of scientific evidence displays how alcohol diminishes key driving skills at BACs $\leqslant 0.05 \%$. A $0.05 \%$ enforced limit in many countries has become an acknowledged deterrent with fewer alcohol fuelled crashes, deaths, and injuries. Supposed difficulties enforcing a lower limit are questionable too, with inflated resource estimates, underestimated cost savings, and overstated practical problems administering the system.

Some dismiss a $0.05 \%$ Criminal Code offence as unnecessary and unworkable when provincial and territorial laws enforcing a $0.05 \%$ BAC already exist. Driving with a BAC $>0.05 \%$ is not illegal under these laws, however, and they cannot have the same deterrence value as a federal offence carrying a fine, driving ban, and a criminal record. Neither would a $0.05 \%$ Criminal Code conflict with provincial laws because the threshold for charging drivers under federal law would be pitched around $0.07 \%$ BAC .

In 2001 Canada's federal government pledged to make its roads the safest anywhere. How it can do so remains to be seen.

A Injury Prevention 2002;8(Suppl III):iii 1-iii 17 